\title{
Dual-Feed Small-Size Penta-Band PIFA for LTE/WWAN Mobile Handset Applications
}

\author{
Mingyang Liu ${ }^{1}$ and Bin Zhao $^{2}$ \\ ${ }^{1}$ College of Instrumentation \& Electrical Engineering, Jilin University, Changchun 130061, China \\ ${ }^{2}$ Jilin Animation Institute, Changchun 130012, China \\ Correspondence should be addressed to Mingyang Liu; liu_myang@163.com
}

Received 31 May 2014; Revised 19 July 2014; Accepted 27 July 2014; Published 25 August 2014

Academic Editor: Renato Cicchetti

Copyright (c) 2014 M. Liu and B. Zhao. This is an open access article distributed under the Creative Commons Attribution License, which permits unrestricted use, distribution, and reproduction in any medium, provided the original work is properly cited.

\begin{abstract}
A dual-feed small-size penta-band PIFA for LTE/WWAN mobile handset applications is presented. The proposed PIFA is composed of a simple U-shaped patch with dual-shorting pins connected to the ground plane. The patch, having a low profile of $5 \mathrm{~mm}$, has dimensions of about $10 \times 35 \mathrm{~mm}^{2}$. The antenna is excited at one arm of the U-shaped radiating patch to cover the higher band of GSM1800/1900/UMTS2100/LTE2300/2500, while it is excited at the other arm to realize the GSM900. In this way, the proposed PIFA achieves enhanced bandwidth coverage with no increased dimensions and additional active switches. In addition, the matching networks, employed on both feeds, ensure a high electrical insulation between the low and the high frequency bands, covered by the antenna. The measured antenna efficiency is $45 \% \sim 50 \%$ and over $60 \%$ for the lower band and the higher band, respectively. A prototype of the proposed PIFA with dual-feed and dual-shorting pins was fabricated. The measured results including reflection coefficients and radiation characteristics are presented.
\end{abstract}

\section{Introduction}

With the rapid growth of the personal communication services, the development of compact and small-size antennas, for multiband operation, has become a fundamental requirement in antenna design. As the touch screen becomes larger and larger in the mobile handsets, the clearance area left for the antenna is becoming smaller and smaller. Accordingly, the mutual coupling between the radiating elements and the ground plane is increased, which leads to a higher quality factor $Q$ and brings more complex challenges to obtain wideband antennas. In this case, PIFA [1-4] is considered as a promising candidate, since its radiative performances are quite independent of the size of the clearance area on the ground plane. However, PIFA usually covers a narrow bandwidth and occupies a large volume, especially for the lower band.

To solve these problems, several methods [5-13] which enhance the bandwidth coverage and reduce the dimensions of dielectric, printed, or PIFA antennas have been proposed in literature. In [5], a low-permittivity dielectric resonator has been used to obtain a wideband antenna. Additional radiating elements, which also increase the complexity of the antenna structure, have been used in [6] to gain wide operating bands. Multishorting pins, which are actually effective in practical applications, have been employed in [7] to expand the bandwidth coverage. The reconfigurable antenna technology has been also applied to enlarge the bandwidth of the PIFAs. In [12-14], the wide bandwidth coverage is obtained by inserting two PIN diodes. Nevertheless, the adoption of active switching or tunable circuits, employed to get wide bandwidth, sometimes degrades the antenna performances due to the intrinsic nonlinearities exhibited by the active switches.

As another effective choice, passive switching methods have been applied in $[15,16]$ to get similar tunable functions as the active switches. In [16], a dual-feed structure, composed of a direct feed and a gap-coupled feed, is employed to enhance the antenna bandwidth. With a small size volume of $5 \times 10 \times 50 \mathrm{~mm}^{3}$, the antenna covers a wide bandwidth coverage for LTE/WWAN operation. Moreover, compared with the active switch methods, the complexity of the antenna structure is much lower and the fabrication is accordingly 


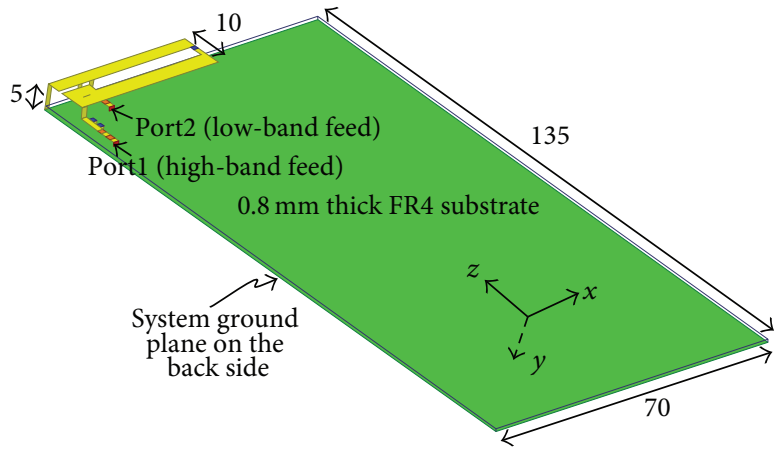

(a)

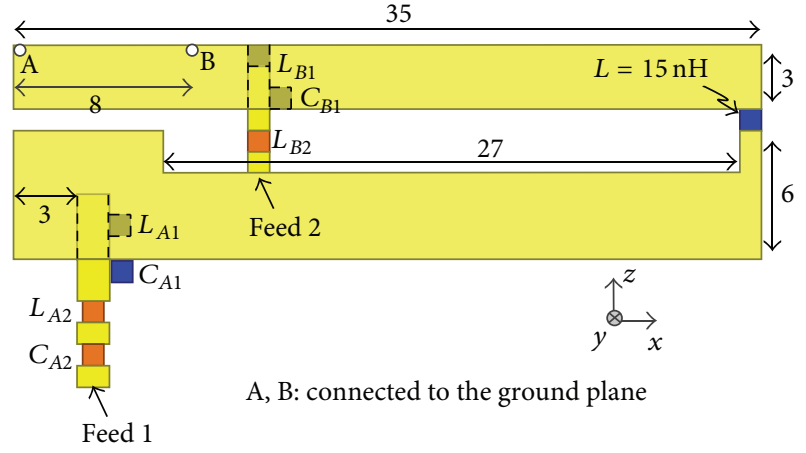

(b)

FIGURE 1: Proposed dual-feed PIFA configuration. (a) Geometry of the PIFA. (b) Detailed dimensions of the PIFA $\left(L_{A 1}=2.2 \mathrm{nH} ; L_{A 2}=6 \mathrm{nH}\right.$; $\left.L_{B 1}=3 \mathrm{nH} ; L_{B 2}=17 \mathrm{nH} ; C_{A 1}=0.9 \mathrm{pF} ; C_{A 2}=2.4 \mathrm{pF} ; C_{B 1}=4 \mathrm{pF}\right)$. All dimensions are in millimeters. The reference system used to analyze the antenna structure is also shown.

easier. Therefore, the passive switching circuit is of great value to realize wideband antennas for mobile handset applications.

In this paper, the passive switching method of two feeds is employed to a simple PIFA for penta-band LTE/WWAN mobile handset applications. The proposed PIFA, having a total size of $35 \times 10 \mathrm{~mm}^{2}$ and a profile of $5 \mathrm{~mm}$, is disposed on a ground plane of $135 \times 70 \mathrm{~mm}^{2}$ which simulates a 5 inch touch screen. It is noted that the proposed PIFA does not require a clearance area on the ground plane and has a much smaller volume than those reported in literature. The low-band feed and the high-band feed which comprise wideband matching networks can cover the lower band (880 $960 \mathrm{MHz})$ and the higher band $(1710 \sim 2690 \mathrm{MHz})$, respectively. Moreover, the matching networks help to achieve a high electrical isolation (more than $20 \mathrm{~dB}$ ) between the two feeds. Fabrication of the dual-feed PIFA is simple and of low cost, and the PIFA has good performances. Detailed considerations concerning the proposed dual-feed PIFA and its operating principles are presented in the next sections.

\section{Proposed PIFA Design}

Figure 1(a) shows the geometry of the proposed PIFA, which has two feeds for the high-band and low-band operation, respectively. The dual-feed PIFA has a total volume of $10 \times$ $35 \times 5 \mathrm{~mm}^{3}$ and is disposed on the left edge of a $0.8 \mathrm{~mm}$ thick FR4 substrate with relative dielectric constant of 4.4 and loss tangent of 0.023 . The size of the ground plane is chosen of about $135 \times 70 \mathrm{~mm}^{2}$. Such dimensions are similar to those of a 5.0 -inch touch screen of a mobile handset. It is also noted that no clearance area on the ground plane is needed. To excite the PIFA, the high-band and low-band feeding points are connected through the via-hole to $50 \Omega$ minicoaxial cables. Detailed dimensions of the dual-feed PIFA are depicted in Figure 1(b), while the dimensions of the two shorting pins are $1 \times 5.8 \mathrm{~mm}^{2}$.

The proposed PIFA is composed of a simple U-shaped radiating patch, two separate feeds with matching networks and two shorting pins. In the proposed PIFA, the radiating patch with one shorting pin resonates at about $1800 \mathrm{MHz}$.
To widen the bandwidth coverage of the higher band, an additional shorting pin is added and a lumped inductor of $15 \mathrm{nH}$ is embedded in the radiating patch. Accordingly, one more resonant mode at about $2750 \mathrm{MHz}$ is generated, covering the GSM1800/1900/UMTS2100/LTE2300/2500 frequency bands. In order to realize the lower-band coverage, the lowband feed is employed with a matching network. By tuning the values of the lumped elements as well as the type of the matching network, a dual-resonance mode can be obtained, covering the GSM900 operation.

To get good isolation between the two feeds, a secondorder band-pass filter synthesized by Advanced Design System (ADS) is incorporated in the high-band feed. With good band-pass characteristics, the incorporation of the filter has little influence on the performances of the antenna. What is more, with good band rejection characteristics, the filter helps to reject the low-band frequency. At the same time, the matching network applied for the low-band feed rejects the high-band frequency. In this case, the isolation between the two feeds is enhanced. Finally, the PIFA succeeds to cover the GSM900/1800/1900/UMTS2100/LTE2300/2500 frequency bands, with an electrical isolation of more than $20 \mathrm{~dB}$ between the two feeds.

To gain physical insight into the radiation mechanisms of the proposed antenna, the magnitude and direction of the surface current distributions, simulated at the frequencies of $925 \mathrm{MHz}, 1800 \mathrm{MHz}$, and $2750 \mathrm{MHz}$, are depicted in Figure 2. From Figure 2(a), it is seen that the surface current on the radiating patch is strongly excited. This suggests that the dual-resonance mode for the lower-band is mainly due to the coupled radiating strips and the matching network. At the same time, the current flowing on the surroundings of the high-band feed is much weaker; this behavior is in accordance with the previous analysis that has put in evidence that there is a high electrical isolation between the two feed points. As shown in Figures 2(b) and 2(c), strong current appears on the radiating patch. This indicates that the $\mathrm{U}$ shaped patch and the connecting pins contribute to a $\lambda / 2$ resonant mode, at about $1800 \mathrm{MHz}$, and to a $3 \lambda / 4$ resonant mode at about $2750 \mathrm{MHz}$, respectively. From Figure 2, it 


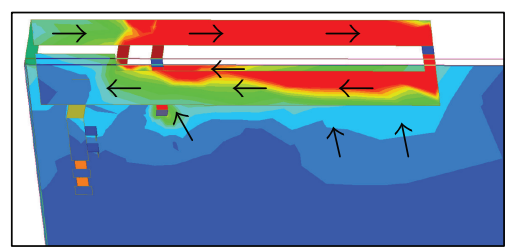

(a)

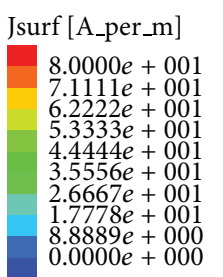

$8.8889 e+000$
$0.0000 e+000$

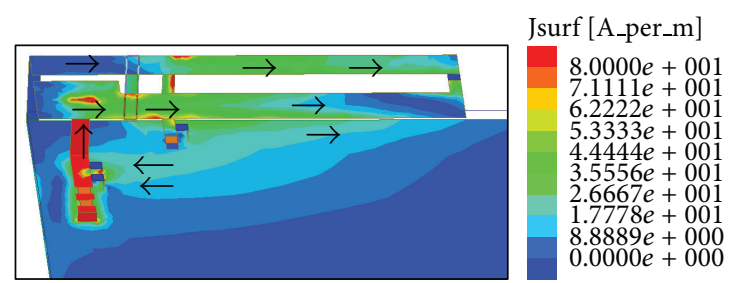

(b)

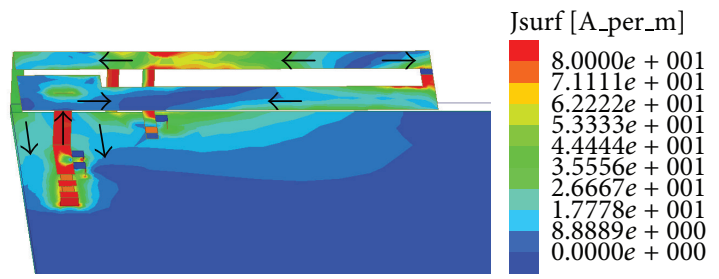

(c)

FIgURE 2: Simulated current distributions at different frequencies: (a) $925 \mathrm{MHz}$, (b) $1800 \mathrm{MHz}$, and (c) $2750 \mathrm{MHz}$.

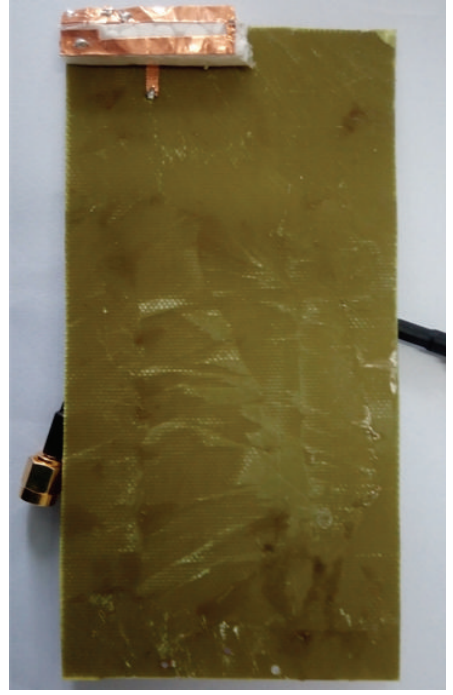

(a)

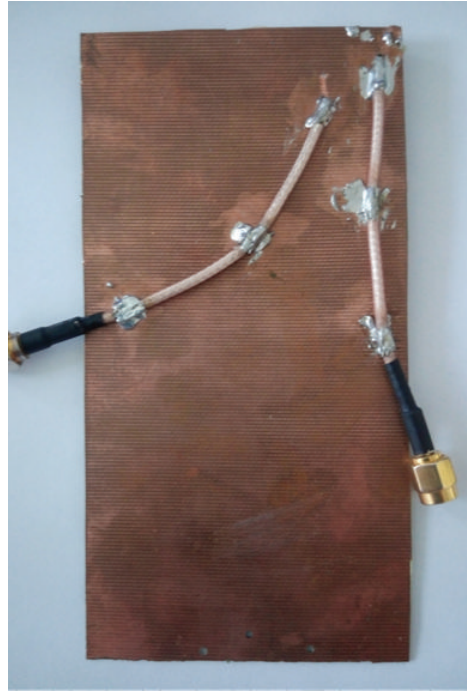

(b)

FIgUre 3: Prototype of the dual-feed PIFA. (a) Top view and (b) bottom view.

is observed that the radiation is substantially concentrated along the U-shaped patch, where the conversion of surface waves into volume waves takes place [17]. What is more, it can also be seen from the current distributions that the two shorting pins have different effects on the resonant modes at different frequencies. Typically, as shown in Figure 2(c), the current on the shorting pin which is close to the lowband feed is much stronger than the other one. Consequently, the optimization of the antenna can be done by tuning the location of the shorting pins.

\section{Numerical Results and Measurements}

The dual-feed PIFA whose prototype is shown in Figure 3 was fabricated and tested. The simulation process is done by using the HFSS version 12.0, and the measured results are achieved by employing the network analyzer Agilent E5071C and the Satimo StarLab far field measurement system. Both the simulated and measured results are depicted in Figure 4, and it is noted that the measured and simulated results are in good agreement, while the small differences observed are found to be related to the manufacture tolerances and with the perturbation effects introduced by the feeding cables. Based on the $-6 \mathrm{~dB}$ return loss which is widely adopted as the design specification of the internal mobile handset antenna, the dual-feed PIFA realizes pentaband operation with a small occupation volume, covering the GSM900/1800/1900/UMTS2100/LTE2300/2500 frequency bands. In addition, the isolation between the highband feed and the low-band feed is more than $20 \mathrm{~dB}$ for all the operating bands. Therefore, the proposed dual-feed PIFA can be adopted for multiband mobile handsets having large touch screens. 


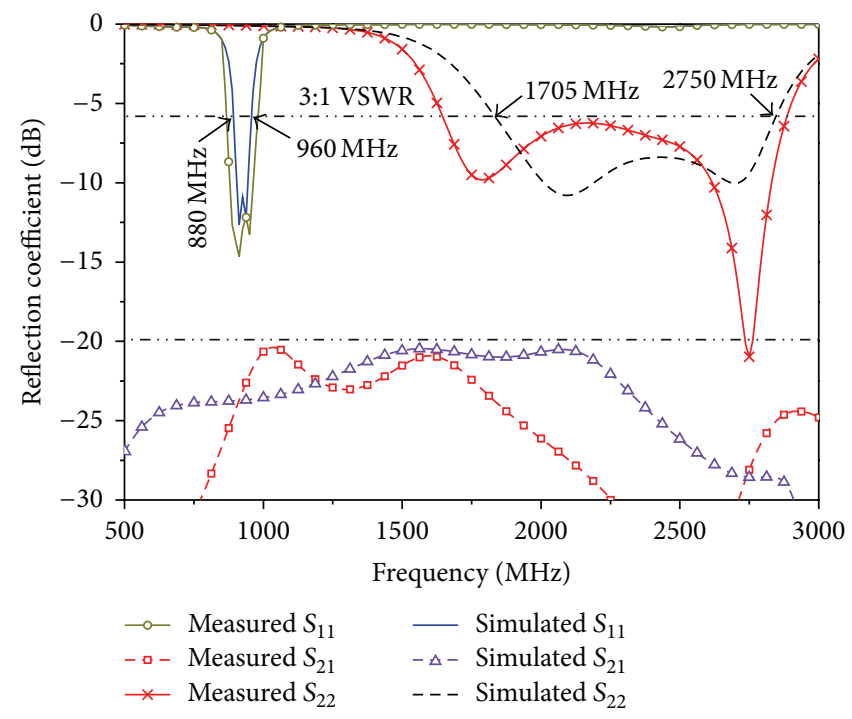

FIGURE 4: Simulated and measured reflection coefficient of the proposed dual-feed PIFA.

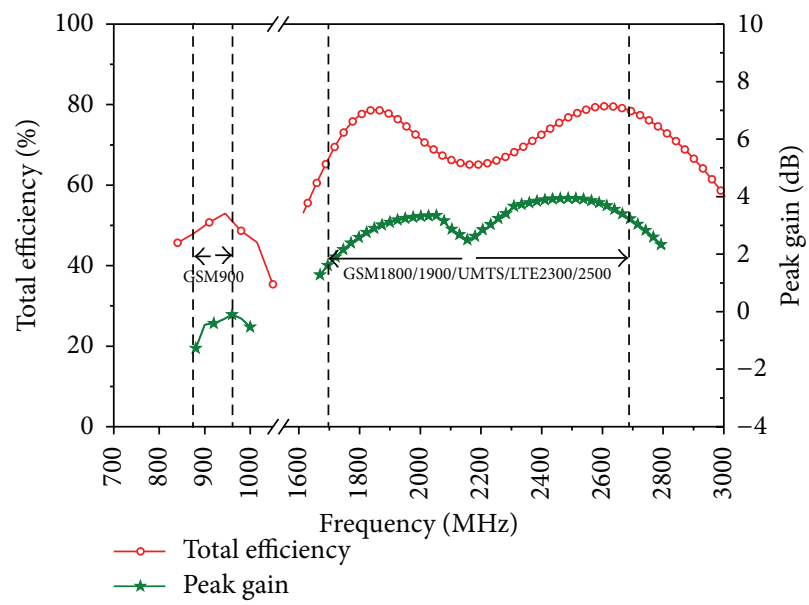

FIGURE 5: Measured total efficiency and peak gain of the proposed PIFA.

The radiation patterns of the proposed PIFA have been also measured in a Satimo StarLab. The measured antenna efficiency including the mismatch losses and peak gain are shown in Figure 5. The antenna efficiency is about 45\% $50 \%$ and over $60 \%$ for the lower and upper band, while the peak gain is about $-1.3 \sim-0.1 \mathrm{~dB}$ and $2.4 \sim 3.9 \mathrm{~dB}$, respectively, confirming that the proposed dual-feed PIFA is applicable to practical mobile handset designs. The $2 \mathrm{D}$ radiation patterns of the proposed dual-feed PIFA measured at 930, 1950, and $2500 \mathrm{MHz}$, in the $x-z, y-z$, and $x-y$ planes, are shown in Figure 6. It is observed that the antenna radiation diagrams are quite omnidirectional at all the frequencies, and this behavior is quite beneficial to practical mobile communications due to the unfixed position of the mobile handset. Consequently, the proposed antenna has good radiation characteristics and is applicable to real wireless communication systems.
Figure 7 shows the numerical models adopted to determine the specific absorption rate (SAR) in different operative situations of the user $[18,19]$, while Table 1 reports the corresponding simulated SAR values for $1 \mathrm{~g}$ head tissues. The referred phantom models are filled with homogeneous materials in this study. Typically, the relative permittivity and conductivity of 20 and $1 \mathrm{~S} / \mathrm{m}$ for human hand model and the relative permittivity and density of 3.5 and $1000 \mathrm{~kg} / \mathrm{m}^{3}$ for human head model have been used in the simulation. Three conditions of the head only, the hand only, and the head and the hand are all studied. In the numerical simulations, the circuit board including the antenna is placed close to the head phantom ear and it is tilted by the vertical line of about $60^{\circ}$. The numerical results reported in Table 1 have been obtained assuming an antenna input power of $24 \mathrm{dBm}(0.25 \mathrm{~W})$ for the GSM900 frequency band and of $21 \mathrm{dBm}(0.125 \mathrm{~W})$ for the GSM1800/1900/UMTS2100/LTE2300/2500 frequency bands. 


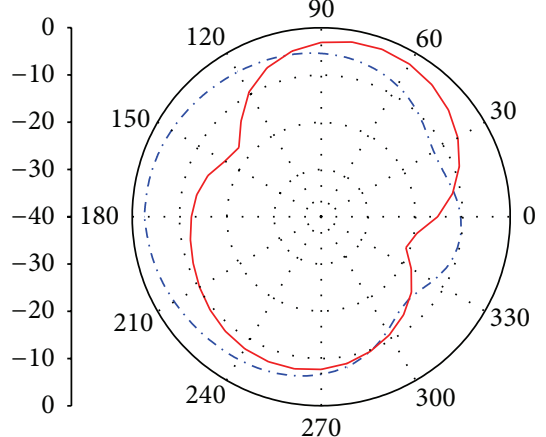

$x-z$

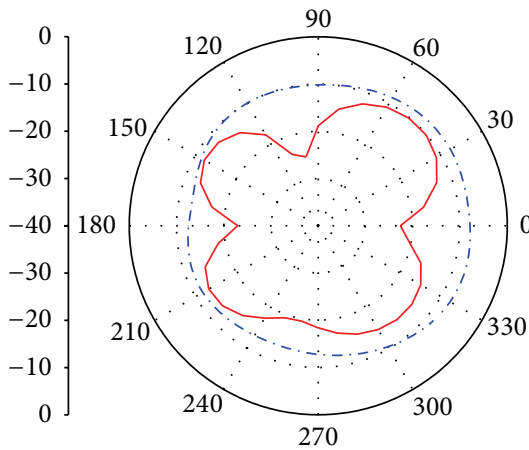

$x-z$

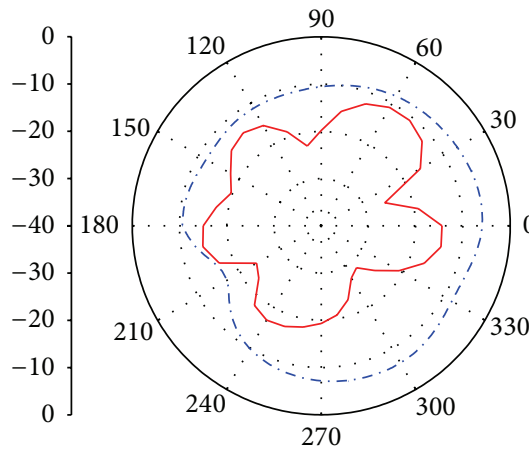

$x-z$

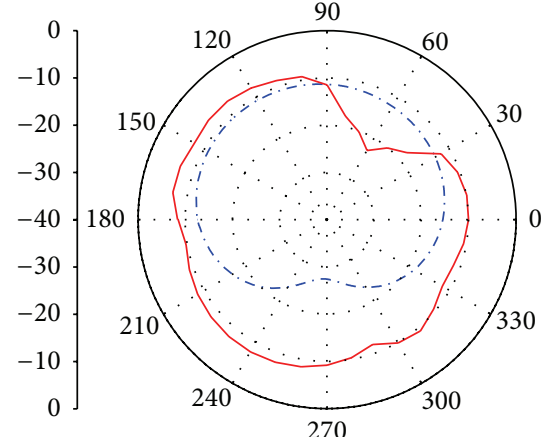

$y-z$

(a) $930 \mathrm{MHz}$
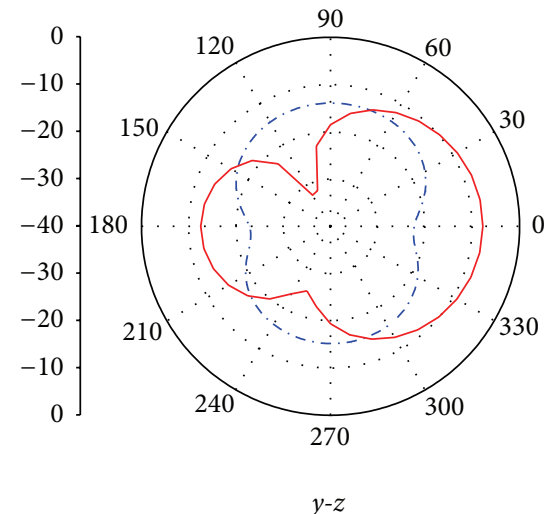

(b) $1950 \mathrm{MHz}$

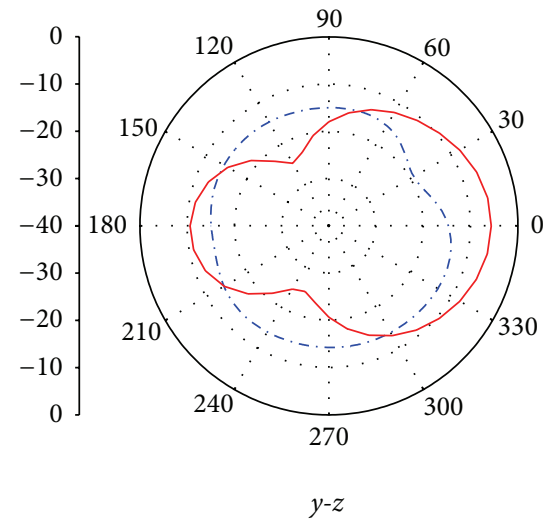

(c) $2500 \mathrm{MHz}$

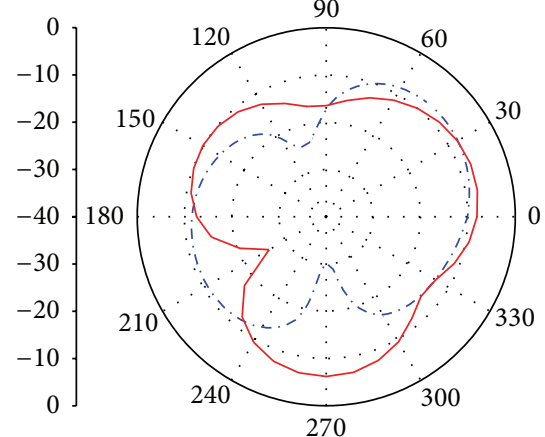

$x-y$

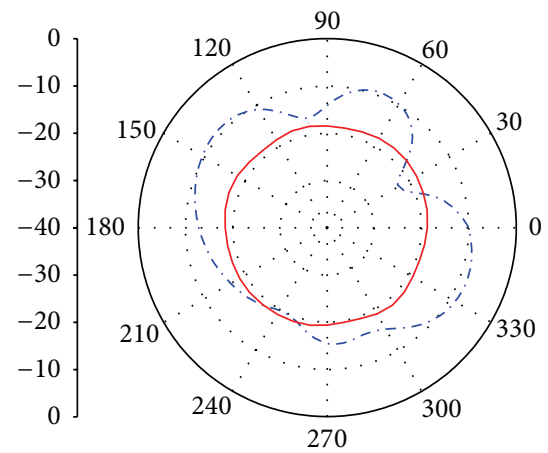

$x-y$

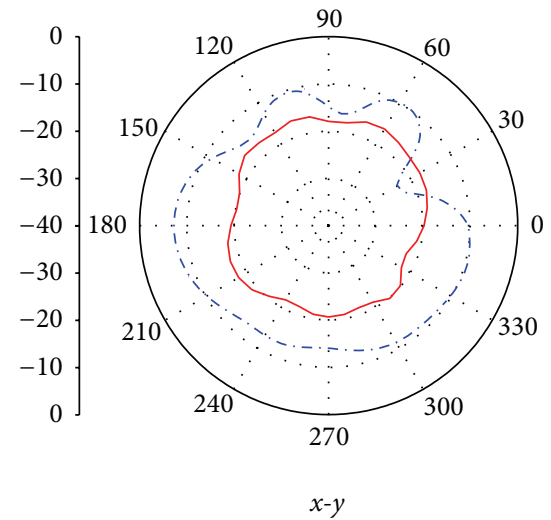

$x-y$

FIGURE 6: Measured normalized 2D radiation patterns: (a) $930 \mathrm{MHz}$, (b) $1950 \mathrm{MHz}$., and (c) $2500 \mathrm{MHz}$ of the proposed dual-feed PIFA (- - $\left.E_{\varphi},-E_{\theta}\right)$.

For the three conditions mentioned above, the $1 \mathrm{~g}$ SAR values are below the SAR limit of $1.6 \mathrm{~W} / \mathrm{Kg}$ for $1 \mathrm{~g}$ tissue, which further suggests that the proposed PIFA is quite suitable for practical mobile handset applications.

\section{Conclusion}

A dual-feed PIFA for penta-band operation for mobile handsets has been presented. The proposed antenna occupies a small volume of about $10 \times 35 \times 5 \mathrm{~mm}^{3}$ and does not require a clearance area on the ground plane. By employing the separate high-band feed and the lowband feed, the PIFA realizes penta-band coverage of the GSM900/1800/1900/UMTS2100/LTE2300/2500 communication standards. In addition, the isolation between the two feeds is enhanced by the application of the matching networks, which also improve the impedance matching of the PIFA. Based on the experimental results, it is observed that the proposed dual-feed PIFA without using active switches has tunable characteristics similar to those of the 


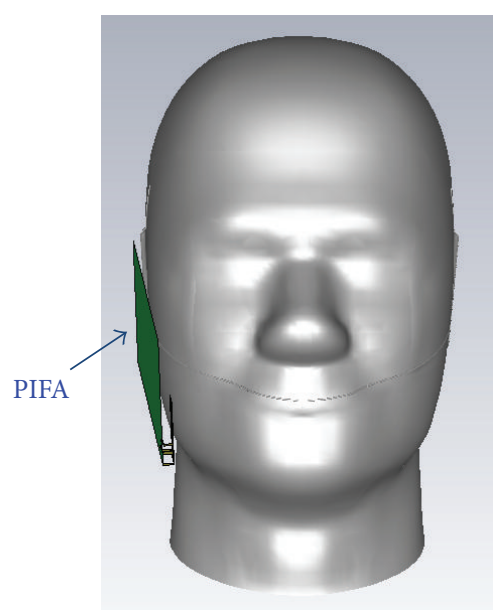

Head only

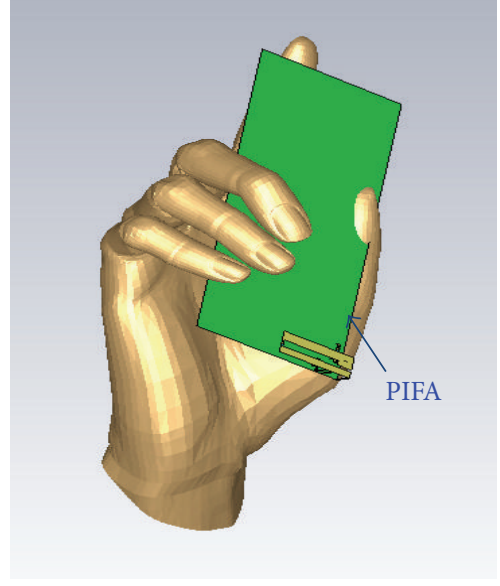

Hand only
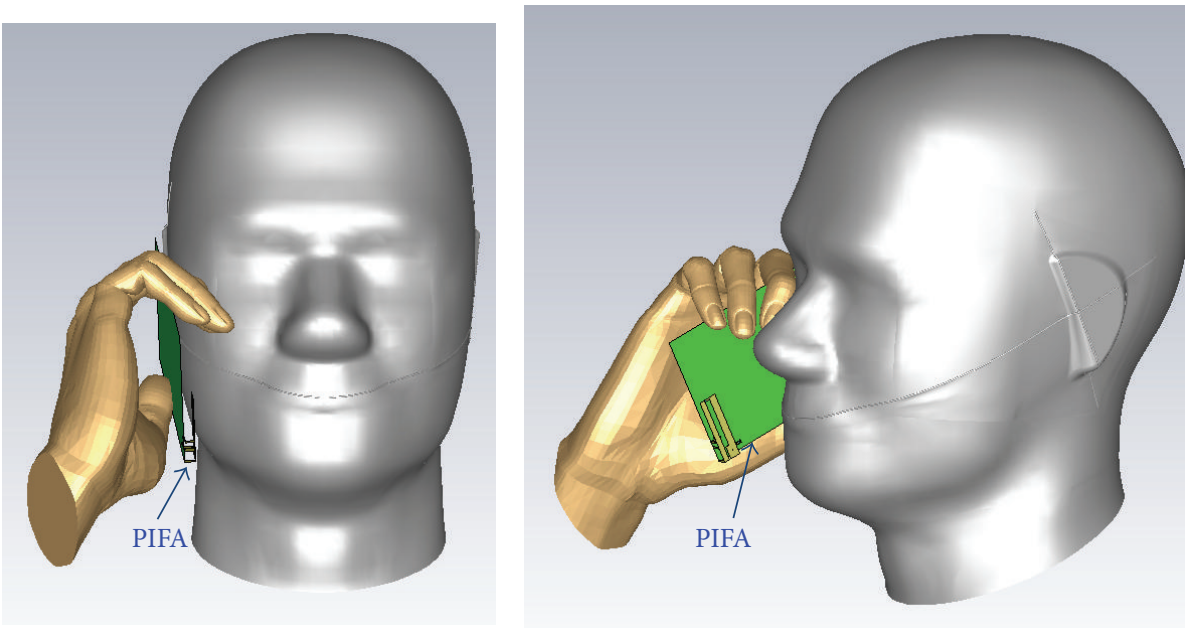

Head and hand

FIGURE 7: SAR simulation model of the proposed dual-feed PIFA.

TABLE 1: Simulated SAR values for $1 \mathrm{~g}$ tissues.

\begin{tabular}{lccccc}
\hline Frequency (MHz) & 900 & 925 & 1750 & 1950 & 2350 \\
\hline 1 g SAR (W/Kg) & & & & & \\
Head only & 1.32 & 1.21 & 0.68 & 0.56 & 0.45 \\
Hand only & 1.35 & 1.18 & 0.75 & 0.64 & 0.52 \\
Head and hand & 1.41 & 1.25 & 0.72 & 0.65 & 0.57 \\
Return loss (dB) & & & & & \\
Head only & 8.9 & 10.5 & 6.6 & 10.8 & 8.7 \\
Hand only & 12.1 & 11.3 & 6.8 & 11.5 & 12.5 \\
Head and hand & 12.5 & 11.1 & 7.1 & 17.2 & 13.6 \\
\hline
\end{tabular}

reconfigurable PIFAs. In addition, the measured radiation patterns prove that the proposed PIFA is suitable for mobile handset applications.

\section{Conflict of Interests}

The authors declare that there is no conflict of interests regarding the publication of this paper.

\section{Acknowledgment}

This project has been granted by Scientific Development Foundation of Jilin Provincial Science \& Technology Department of China (no. 20130305020GX).

\section{References}

[1] D. M. H. Elsheakh, A. M. Soliman, and E. A. Abdallah, "Low specific absorption rate hexa-band coplanar waveguidefed planar inverted-F antenna with independent resonant frequency control for wireless communication applications," IEE 
Proceedings-Microwaves, Antennas and Propagation, vol. 8, pp. 207-216, 2014.

[2] M. Abri, N. Belgacem, and W. Belgacem, "New GSM, DCS and GSM/DCS Pifa antennna for wireless networks applications," Internal Journal of Information Network security, vol. 2, no. 4, pp. 305-310, 2013.

[3] H.-W. Liu and C.-F. Yang, "Miniature PIFA without empty space for $2.4 \mathrm{GHz}$ ISM band applications," Electronics Letters, vol. 46, no. 2, pp. 113-115, 2010.

[4] D. M. Nashaat, H. A. Elsadek, and H. Ghali, "Single feed compact quad-band PIFA antenna for wireless communication applications," IEEE Transactions on Antennas and Propagation, vol. 53, no. 8, pp. 2631-2635, 2005.

[5] M. Simeoni, R. Cicchetti, A. Yarovoy, and D. Caratelli, "Plasticbased supershaped dielectric resonator antennas for wide-band applications," IEEE Transactions on Antennas and Propagation, vol. 59, no. 12, pp. 4820-4825, 2011.

[6] J. H. Lee and J. G. Yook, "Improvement of radiation performance of mobile phone antenna using parasitic element," IEEE Transactions on Consumer Electronics, vol. 56, no. 4, pp. 24112415, 2010.

[7] M. S. Ahmad, C. Y. Kim, and J. G. Park, "Multishorting pins PIFA design for multiband communications," International Journal of Antennas and Propagation, vol. 2014, Article ID 403871, 10 pages, 2014.

[8] K. L. Wong, Y. W. Chang, and S. C. Chen, "Bandwidth enhancement of small-size planar tablet computer antenna using a parallel-resonant spiral slit," IEEE Transactions on Antennas and Propagation, vol. 60, no. 4, pp. 1705-1711, 2012.

[9] H. T. Chattha, Y. Huang, and Y. Lu, "PIFA bandwidth enhancement active high impedance surface for low profile tunable and steerable antennas," IEEE Antennas and Wireless Propagation Letters, vol. 8, pp. 637-640, 2009.

[10] D. Caratelli, R. Cicchetti, G. Bit-Babik, and A. Faraone, "A perturbed E-shaped patch antenna for wideband WLAN applications," IEEE Transactions on Antennas and Propagation, vol. 54, no. 6, pp. 1871-1874, 2006.

[11] K. L. Wong and Y. C. Liu, "Small-size WWAN tablet computer antenna with distributed and lumped parallel resonant circuits," Microwave and Optical Technology Letters, vol. 54, no. 6, pp. 1348-1353, 2012.

[12] H. F. AbuTarboush, R. Nilavalan, T. Peter, S. W. Cheung, and D. Budimir, "Reconfigurable penta-band pifa for small and slim mobile handsets," Microwave and Optical Technology Letters, vol. 54, no. 3, pp. 725-729, 2012.

[13] C. Y. Chiu, K. M. Shum, and C. H. Chan, "A tunable viapatch loaded PIFA with size reduction," IEEE Transactions on Antennas and Propagation, vol. 55, no. 1, pp. 65-71, 2007.

[14] Y. K. Park and Y. Sung, "A reconfigurable antenna for quad-band mobile handset applications," IEEE Transactions on Antennas and Propagation, vol. 60, no. 6, pp. 3003-3006, 2012.

[15] P. Lin and K. Wong, "Dual-feed small-size LTE/WWAN strip monopole antenna for tablet computer applications," Microwave and Optical Technology Letters, vol. 55, no. 11, pp. 2571-2576, 2013.

[16] K.-L. Wong and L.-Y. Chen, "Small-size LTE/WWAN tablet device antenna with two hybrid feeds," IEEE Transactions on Antennas and Propagation, vol. 62, no. 6, pp. 2926-2934, 2014.

[17] D. Caratelli, R. Cicchetti, G. Bit-Babik, and A. Faraone, "Circuit model and near-field behavior of a novel patch antenna for WWLAN applications," Microwave and Optical Technology Letters, vol. 49, no. 1, pp. 97-100, 2007.
[18] M. Ali, M. G. Douglas, A. T. M. Sayem, A. Faraone, and C. K. Chou, "Threshold power of canonical antennas for inducing SAR at compliance limits in the $300-3000 \mathrm{MHz}$ frequency range," IEEE Transactions on Electromagnetic Compatibility, vol. 49, no. 1, pp. 143-152, 2007.

[19] K. Zhao, S. Zhang, Z. N. Ying, T. Bolin, and S. He, "SAR study of different MIMO antenna designs for LTE application in smart mobile handsets," IEEE Transactions on Antennas and Propagation, vol. 61, no. 6, pp. 3270-3279, 2013. 

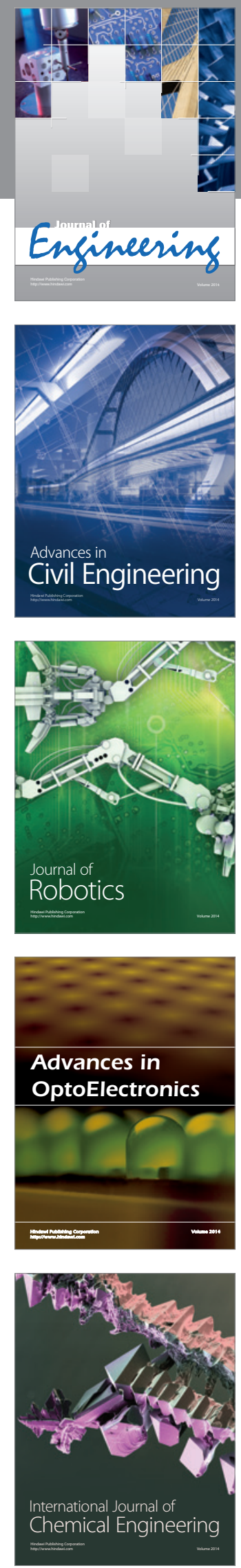

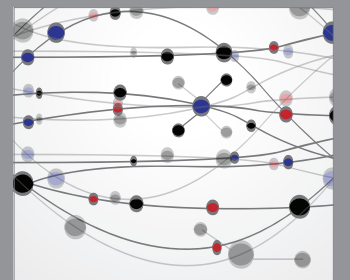

The Scientific World Journal
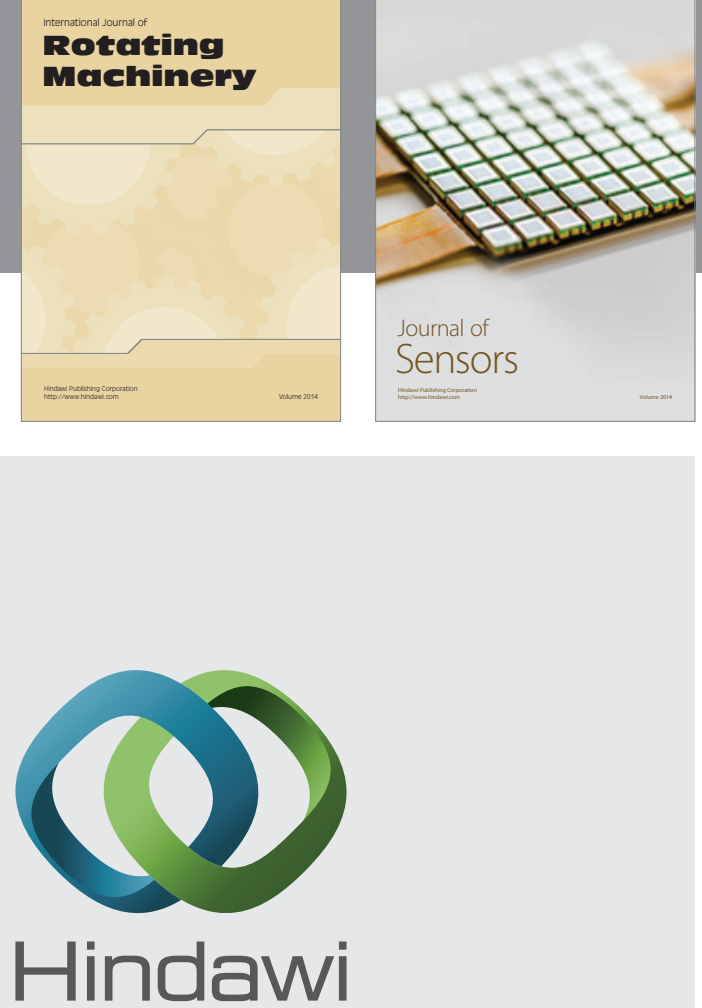

Submit your manuscripts at http://www.hindawi.com
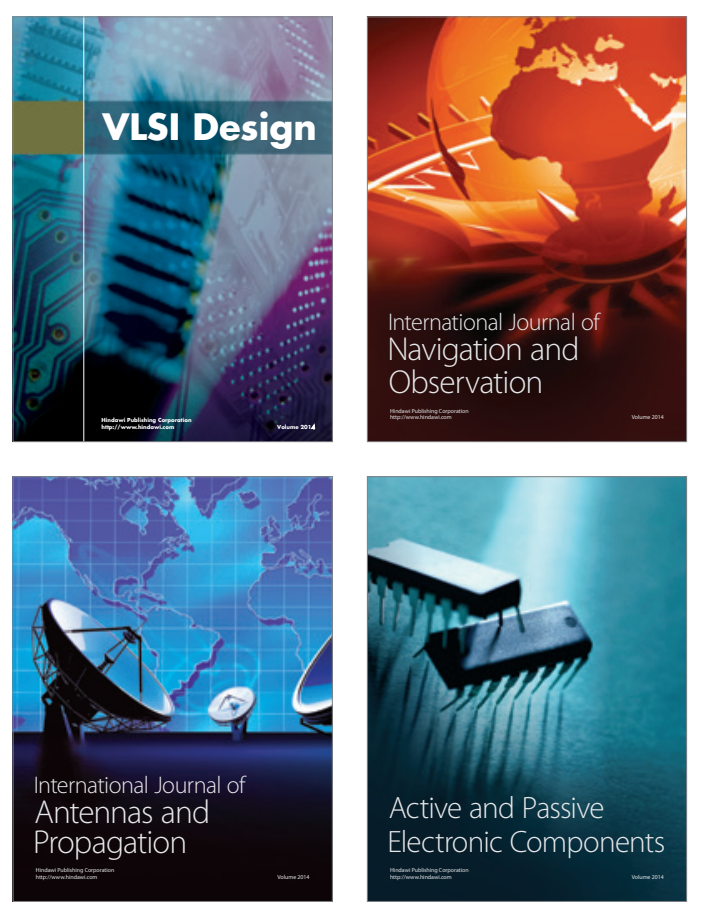
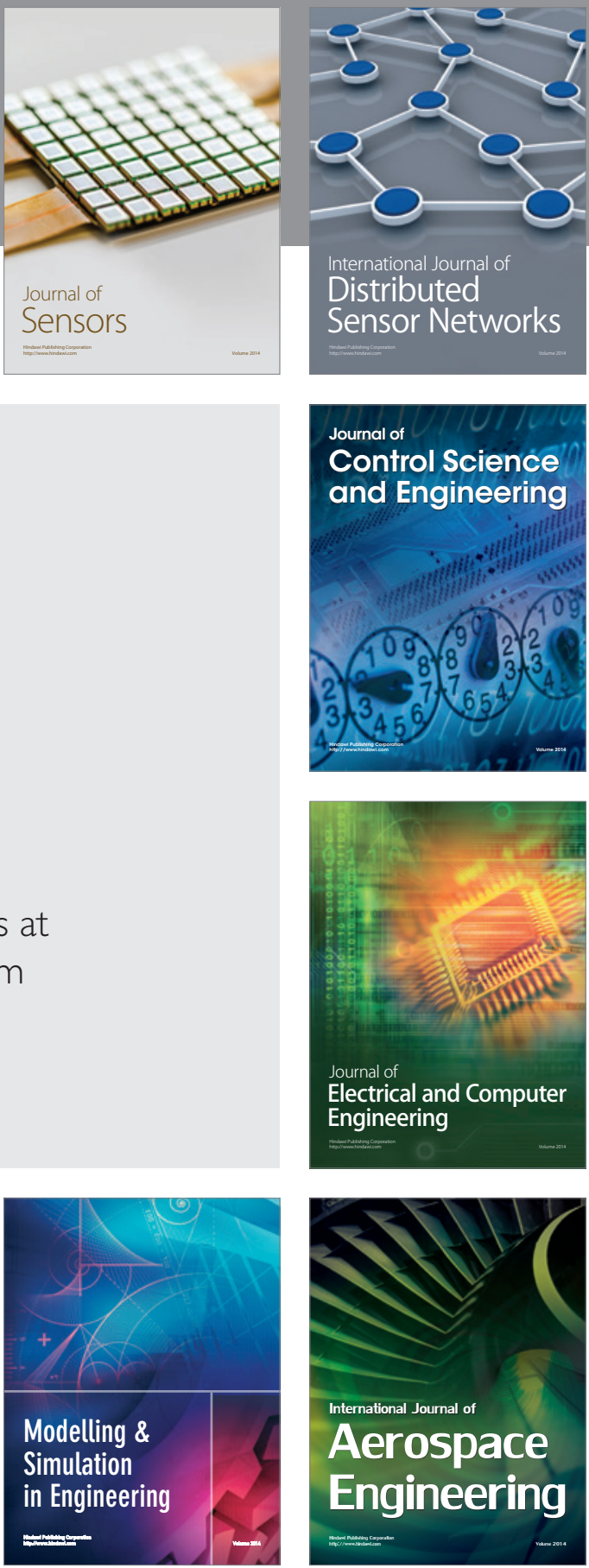

Journal of

Control Science

and Engineering
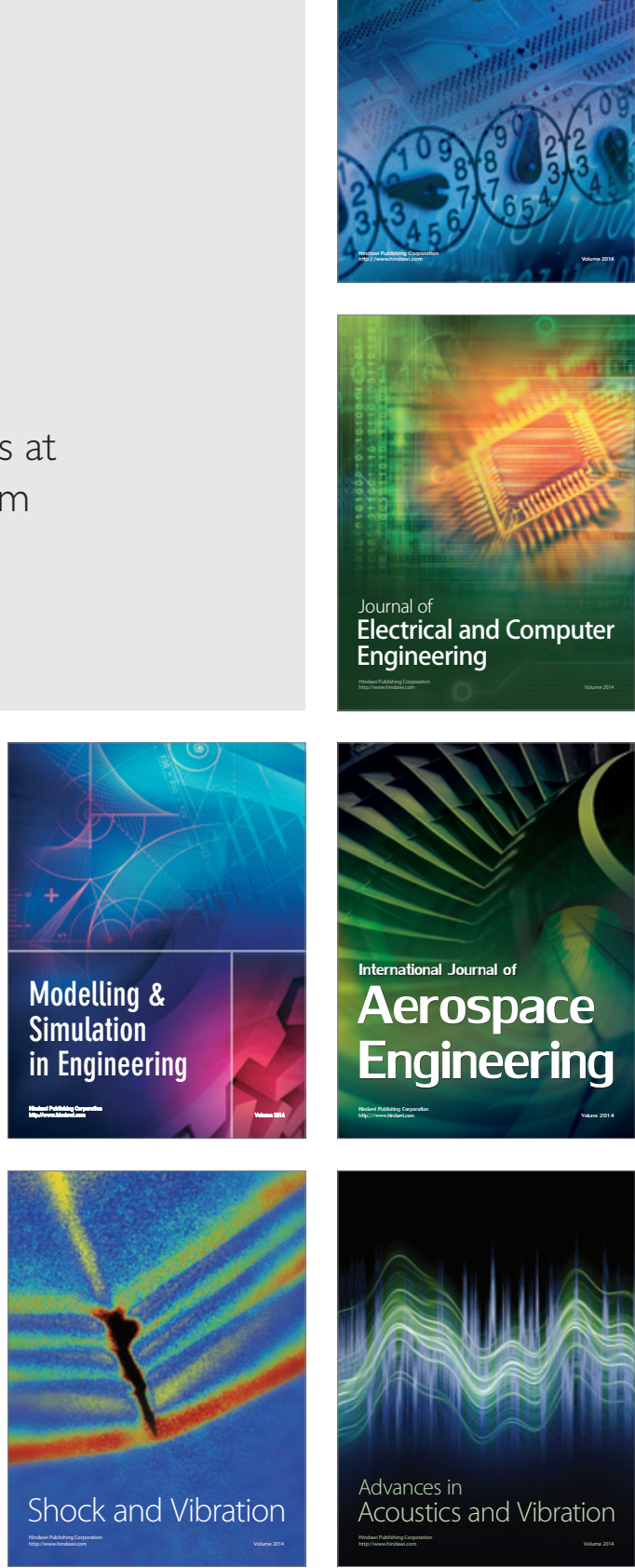